Supporting Information

\title{
Chemical Vapor Deposition of Two-dimensional Boron Sheets by Thermal Decomposition of Diborane
}

\author{
Ali Mazaheri, Mohammad Javadi, and Yaser Abdi* \\ Nanophysics research laboratory, department of physics, University of Tehran, \\ Tehran 14395-547, Iran \\ *Corresponding author: y.abdi@ut.ac.ir
}




\section{MATERIAL CHARACTERIZATION}

Surface topographic data were provided by NTMDT-SOLVER-TS-150 atomic force microscope. As-prepared borophene sheets were transferred onto double-side-polished silicon substrates for topographic measurements. Morphological studies of the as-prepared samples were performed by HITACHI-4160 and NOVA-NANOSEM-450 scanning electron microscopes. A BRUKER-XFlash-6|10 detector was used for energy-dispersive spectroscopy (EDS). For TEM and HRTEM characterizations, 2D boron sheets were transferred onto carbon-coated copper grids. Structural characterizations, electron diffraction, and lattice images were acquired by PHILIPS-CM30 and FEI-TECNAI-G2 transmission electron microscopes. X-ray photoelectron spectroscopy was carried out by X-ray-BESTEC equipped with an aluminum Ka source at energy of $1486.6 \mathrm{eV}$. 


\section{DIBORANE PRODUCTION AND GROWTH CONDITIONS}

A small home-made vacuum chamber was used to produce diborane (figure S1). The chamber was placed in an ice pool and evacuated to a pressure of $10^{-3}$ mbar. Then $\mathrm{NaBH}_{4}$ powder $(2 \mathrm{~g})$ was poured slowly into $\mathrm{H}_{2} \mathrm{SO}_{4}(10 \mathrm{~mL})$ by a mechanical feedthrough. The reaction of sodium borohydride and sulfuric acid produces diborane according to

$$
\mathrm{H}_{2} \mathrm{SO}_{4}(\mathrm{l})+\mathrm{NaBH}_{4}(\mathrm{~s}) \rightarrow \mathrm{NaSO}_{4}(\mathrm{~s})+\mathrm{H}_{2}(\mathrm{~g})+\mathrm{B}_{2} \mathrm{H}_{6}(\mathrm{~g})
$$

(CAUTION! This reaction is exothermic, and explosive if carried out in the presence of oxygen.) After initiating the reaction, the chamber remained connected to the vacuum pump for five minutes. Then it was disconnected from the vacuum pump, and the product gasses (volume fraction: $25 \% \mathrm{~B}_{2} \mathrm{H}_{6}$ and $75 \% \mathrm{H}_{2}$ ) were guided toward the CVD chamber through a spiral tube. The spiral tube (two meters long) was cooled with ice and water to condensed unwanted acid vapors in the exhaust gas. The absence of sulfur or sodium impurities in the final samples was confirmed by energy-dispersive spectroscopy (figure S2). 


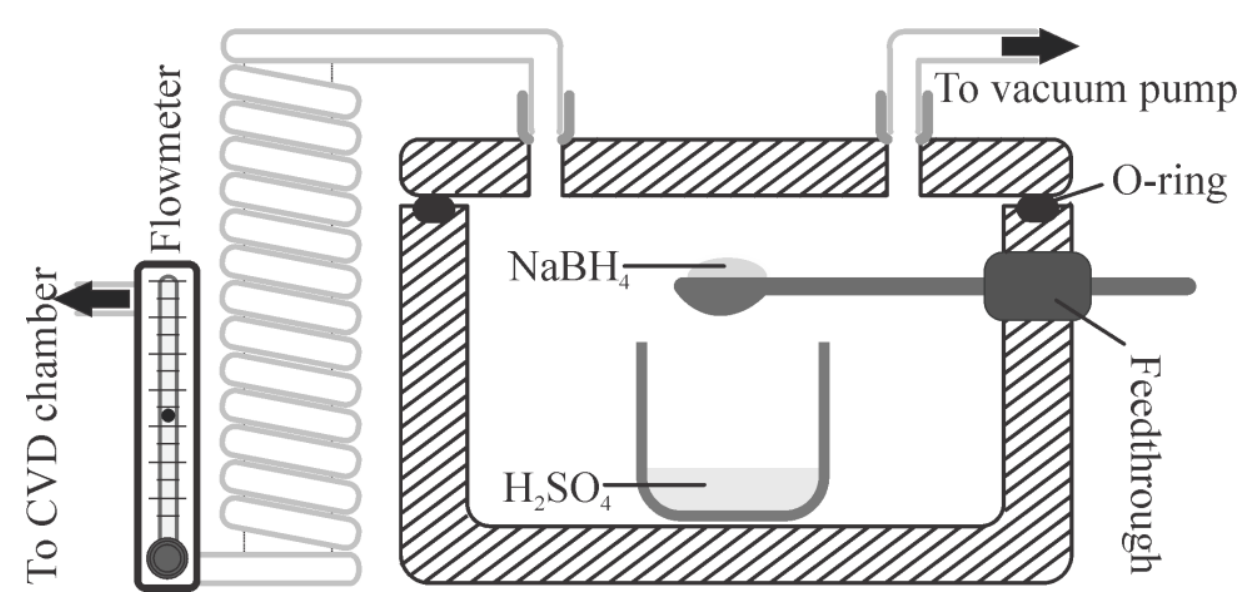

Figure S1. Schematic representation of the diborane production chamber.
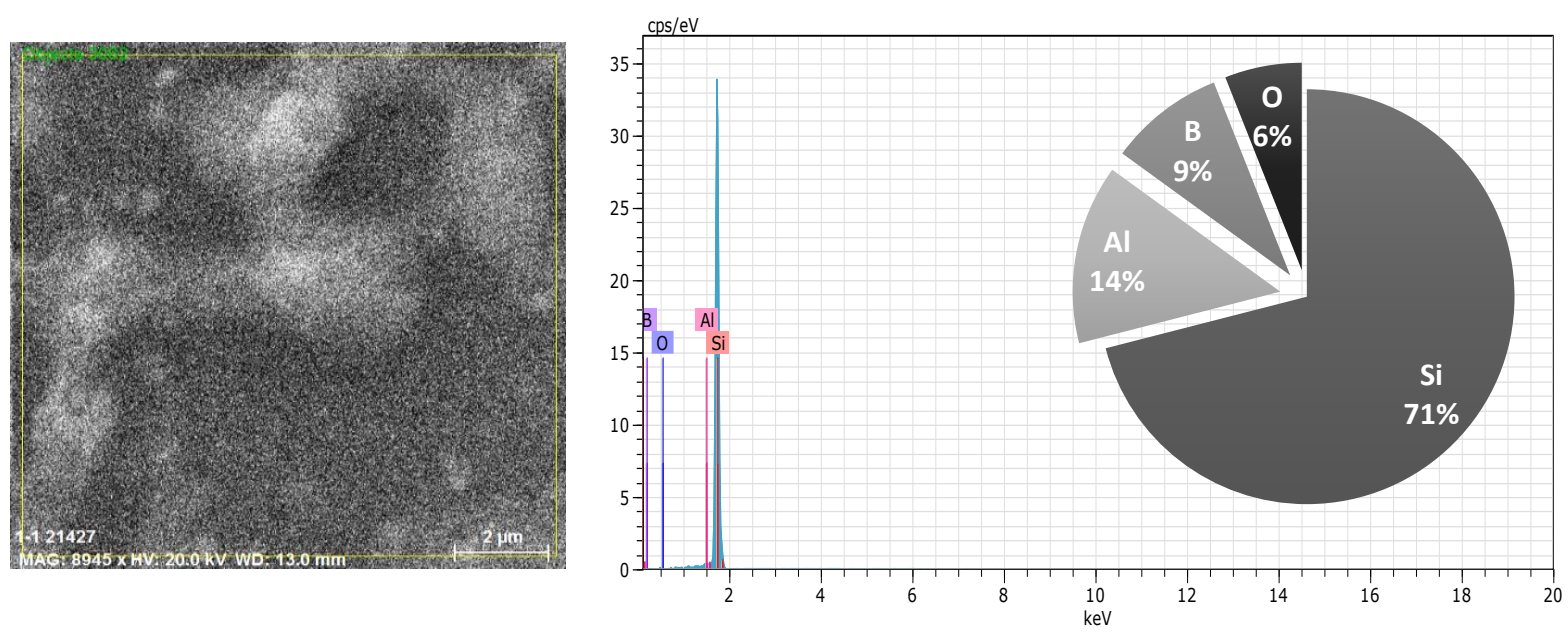

Figure S2. EDS elemental analysis of an as-prepared borophene sheet on $\mathrm{SiO}_{2} / \mathrm{Si}$ substrate.

Figure $\mathrm{S} 3$ represents temperature and pressure of the CVD camber alongside the flow rate of $\mathrm{H}_{2} \mathrm{~B}_{6}$ and $\mathrm{H}_{2}$ carrier (from diborane reaction plus an externally injected $\mathrm{H}_{2}$ source) as a function of time. The temperature was ramped to $830 \mathrm{~K}$ in $15 \mathrm{~min}$. The black arrow in the figure indicates the growth interval at which solid boron atoms from diborane pyrolysis dissolve onto the hot metal and develop 2D boron crystals. At the end of the procedure, the furnace was cooled down to room temperature in 3 hours. 


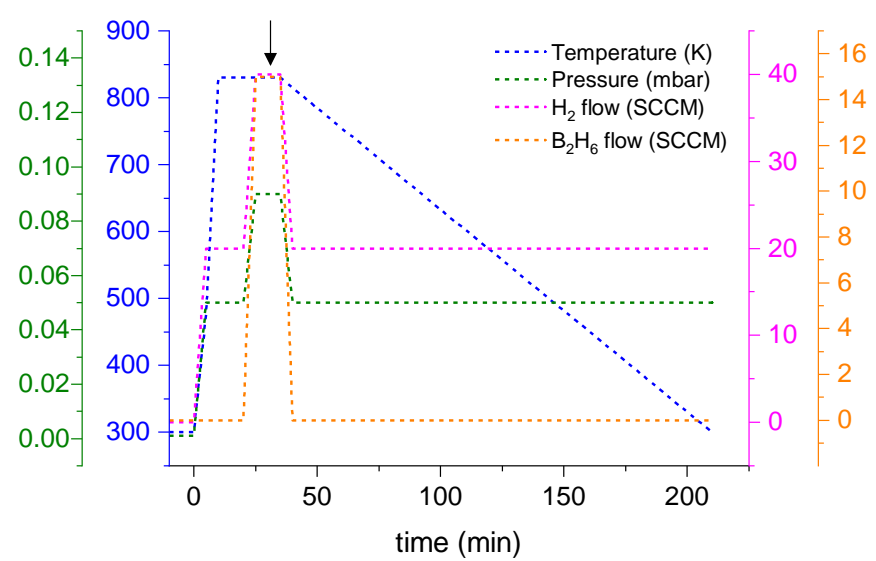

Figure S3. Temperature and pressure of the CVD chamber and flow rate of $\mathrm{H}_{2} \mathrm{~B}_{6}$ and $\mathrm{H}_{2}$ versus time.

\section{TRANSFER METHOD}

We develop a method to separate borophene sheets from the surrounding aluminum aggregations and transfer them onto desired substrates (figure S4). At first, two small pieces of scotch tape were pasted onto the edges of an as-prepared sample, followed by polymethyl methacrylate (PMMA) spun cast onto the sample surface (2000 rpm, 30 seconds). Then the sample was heated at $360 \mathrm{~K}$ for 5 minutes. This heating results in good adhesion of the borophene sheets to the polymer layer. After removing scotch tapes, the edge of the PMMA layer was carefully immersed into hydrochloric acid for a few seconds to remove aluminum aggregations from the sample edge. The sample was then gently transferred onto the distilled water. Owing to relative higher density, the $\mathrm{SiO}_{2} / \mathrm{Si}$ substrate tends to sink into the water while the PMMA layer resists against sinking due to its hydrophobicity nature. These opposite forces finally lead to the separation of the polymer from the substrate. After a short time, the $\mathrm{SiO}_{2} / \mathrm{Si}$ substrate sinks into the distilled water 
while the PMMA layer remains floating, which is then transferred onto the final substrate by dip coating. Finally, the PMMA was removed by acetone leaving isolated borophene sheets onto the desired substrate. Through this process, borophene sheets are transferred with PMMA due to their poor adhesion to the substrate. In contrast, aluminum islands sink into the water with the $\mathrm{SiO}_{2} / \mathrm{Si}$ substrate for their strong adhesion to $\mathrm{SiO}_{2}$.
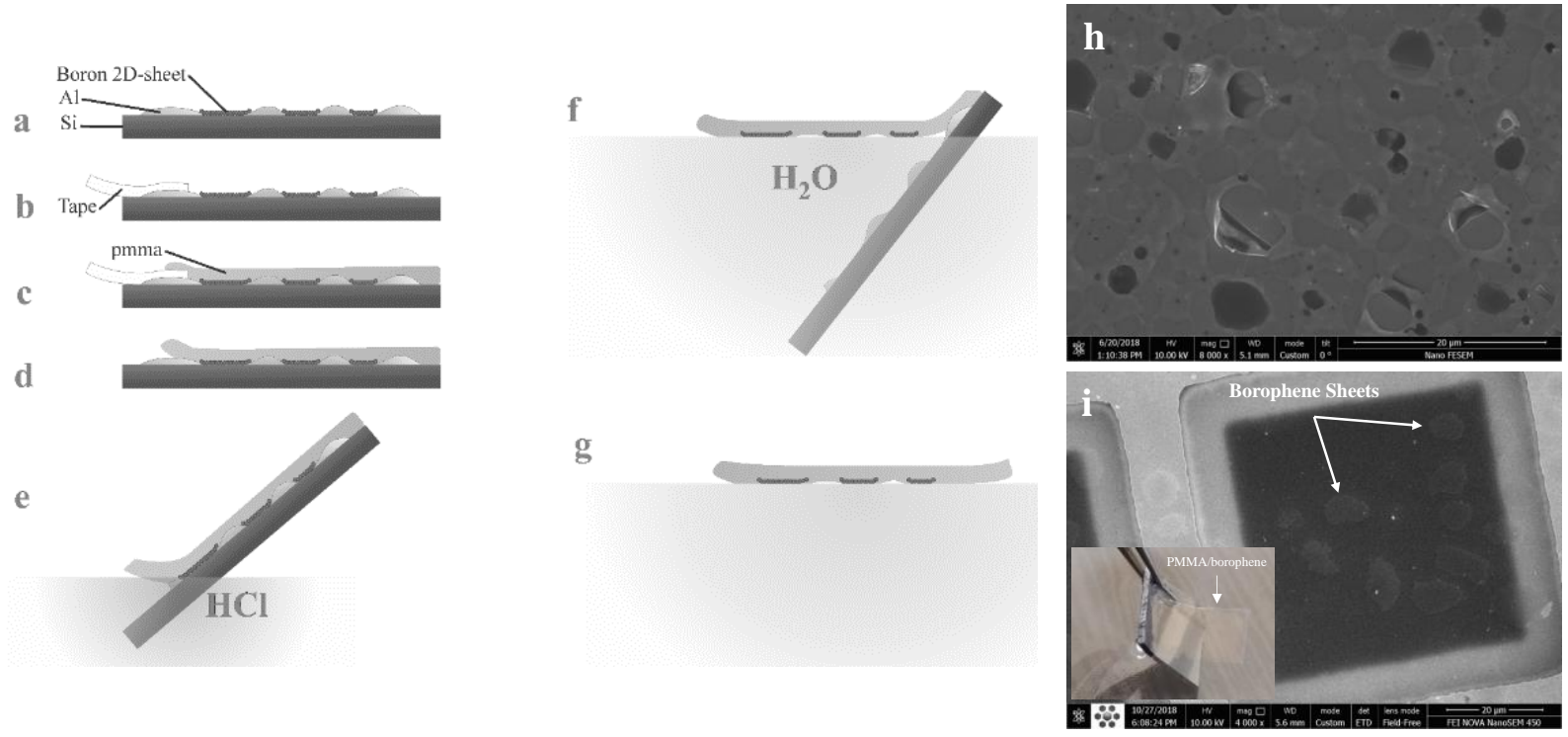

Figure S4. (a-g) The separation of borophene sheets from the surrounding $\mathrm{Al}$ islands and $\mathrm{SiO}_{2}$ substrate. (h, i) SEM images of borophene sheets before and after separation from the $\mathrm{SiO}_{2}$ substrate, respectively. The inset shows an optical image of a PMMA layer separated from the $\mathrm{SiO}_{2} / \mathrm{Si}$ substrate. 


\section{THE EFFECT OF TEMPERATURE ON THE GROWTH OF BOROPHENE}

Figure S5 shows SEM images of as-prepared samples at different temperatures of the CVD chamber. The growth of monolayer borophene sheets is achieved at $830<\mathrm{T}<860 \mathrm{~K}$. At the lower temperatures, the aluminum layer remains almost unaffected. On the other hand, at temperatures higher than $860 \mathrm{~K}$, three-dimensional boron nanostructures are grown.

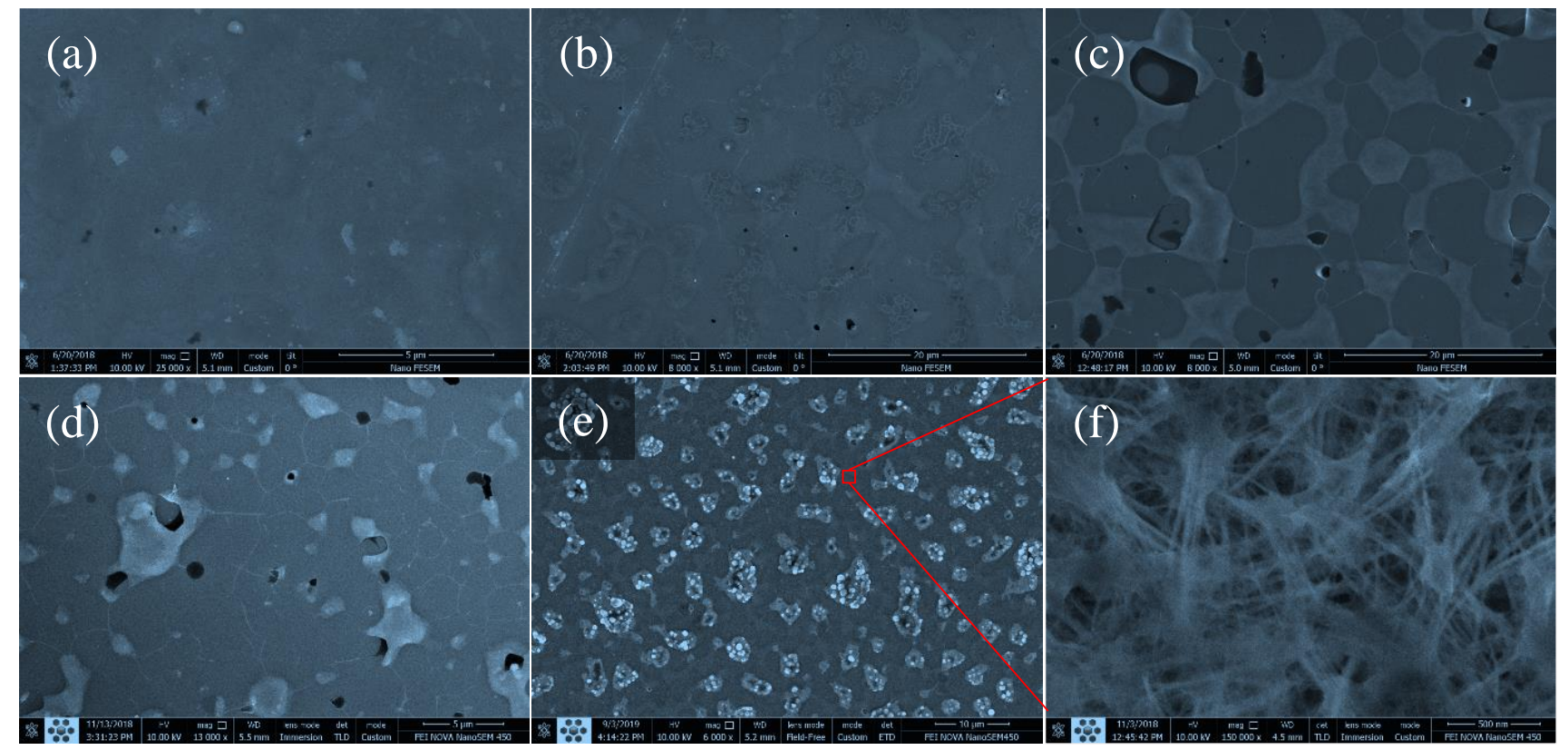

Figure S5. Morphology evolution with growth temperature. SEM images of as-prepared samples at the growth temperature of (a) $770 \mathrm{~K}$ (b) $800 \mathrm{~K}$ (c) $830 \mathrm{~K}$ (d) $860 \mathrm{~K}$ and (e) $890 \mathrm{~K}$. (f) Three-dimensional network of boron nanostructures. 